\title{
Carnaval em Andamento: Hibridismo Cultural no Contexto Carnavalesco de Bagé RS
}

\author{
Carnaval em Curso: la Hibridación Cultural en el Contexto Carnavalesco
}

Bage RS

Carnival in Progress: Cultural Hybridity in the Carnival Context of Bage $R S$

\author{
Rafael Rosa da Silva ${ }^{1}$
}

\begin{abstract}
Resumo
Diversas são as discussões e os estudos em torno do carnaval no Brasil, talvez devido às diversas manifestações existentes nesse período e que variam de um estado para o outro, ou mesmo por ser um campo de estudo que traz em si uma pluralidade de aspectos que podem ser analisados em diversas áreas do conhecimento. A respeito do carnaval no Rio Grande Do Sul, existem poucos trabalhos, principalmente no que diz respeito ao carnaval interiorano. Sendo assim, este trabalho procura discutir acerca dos processos de transformação que o samba, na esfera do Bloco Burlesco Brasa Viva, vem sofrendo no carnaval de rua de Bagé RS. Trazer o samba como um processo em constante mudança não só na esfera carnavalesca, mas também no dia a dia de uma parcela da população brasileira é também poder entender um gênero musical que sofre um processo de hibridismo cultural. Trabalhando com bibliografias acerca da temática do carnaval, atrelada ao contexto de inserção do Bloco Burlesco Brasa Viva, percebemos que ao longo dos anos o samba foi sofrendo um processo hibridização, acompanhado por diversas transformações que acabaram padronizando o samba no carnaval de rua de Bagé RS.
\end{abstract}

Palavras-chaves: Bagé, Carnaval, globalização, Hibridismo cultural, samba.

\section{Resumen}

Son diversas las discusiones y los estudios concernientes al carnaval en Brasil, quizá ello se deba a las múltiples manifestaciones existentes en este periodo, las que varían de un Estado al otro, o inclusive por ser un campo de estudio que conlleva una pluralidad de aspectos que pueden ser analizados en diversas áreas del conocimiento. En lo que respecta al carnaval en Rio Grande do Sul, existen pocos trabajos académicos, máxime cuando dicho asunto trata el carnaval del interior de dicho Estado. Así, este trabajo pretende discutir los procesos de transformación que el samba, en la esfera del Bloco Burlesco Brasa Viva, ha venido sufriendo en el carnaval de calle en Bagé, RS. Abordar al samba como un proceso em constante cambio no solo en la esfera carnavalesca, pero también en lo cotidiano de una parcela de la población brasilera, significa igualmente poder entender un género musical que se impregna de un proceso de hibridismo cultural. Trabajando con una bibliografía que aborda la temática carnavalesca, vinculándola al contexto en que se insiere el Bloco Burlesco Brasa Viva, percibimos que a lo largo de los años el samba ha venido acusando un proceso de hibridación, concomitante con diversas transformaciones que han culminado estandarizando al samba en el carnaval de calle en Bagé, RS.

Palabras Clave: Bagé, Carnava, Globalización, Hibridismo cultural, Samba

\begin{abstract}
There are several discussions and studies around the carnival in Brazil, perhaps due to the different existing manifestations in this period and which vary from state to state, or even to be a field of study that carries a plurality of aspects that can be analyzed in various areas of knowledge. Regarding the carnival in Rio Grande do Sul, there are few studies, especially with regard to small-town carnival. Thus, this paper discusses about the
\end{abstract}

\footnotetext{
${ }^{1}$ Universidade Federal do Pampa (UNIPAMPA). E-mail: rafarosasilva@gmail.com.
} 
transformation processes that samba, in the sphere of block Burlesco Brasa Viva, has suffered in carnival street from Bagé RS. Bring to samba as a process changing not only the carnival ball, but also on the day of a portion of the population is also able to understand a musical genre that suffers a cultural hybridity process. Working with bibliographies on the carnival theme, linked to the context of bloco Burlesco Brasa Viva, we realized that over the years the samba was undergoing a hybridization process, accompanied by several transformations that standardizes the samba in street carnival in Bagé RS.

Keywords: Bagé, Carnival, globalization, cultural hybridity, samba.

\section{Contextualizando o carnaval de rua de Bagé RS.}

O Bloco Burlesco Brasa Viva é uma entidade da cidade de Bagé, no Rio Grande do Sul, localizado na comunidade do Alto da Santa Casa ${ }^{2}$. Fundado em 1968 por moradores do Alto e jogadores do time de futebol amador SER Aimoré ${ }^{3}$ (Sociedade Esportiva Recreativa Aimoré), a entidade teve duas gerações, sendo a primeira pertencente à década de 1960, quando desfilava apenas pelos bairros vizinhos no período de carnaval e a segunda a partir da década de 1980, mais precisamente 1984, quando o bloco decide entrar no cenário competitivo do carnaval Bageense, na categoria dos Blocos Burlescos.

O carnaval de rua de Bagé atualmente é dividido em três categorias, sendo elas Burlesco, Carnavalesco e Escolas de Samba. Para as três categorias, há itens a serem julgados por jurados oriundos de outras cidades, colocando como objetivo principal a realização de um desfile com critérios a serem atingidos. O Brasa Viva, além de ser um dos blocos Burlescos mais antigos de Bagé, é também o detentor da maior série de títulos conquistados em sequência, pois foi campeão de 1985 a 1991, contabilizando sete títulos.

Maia (2008) ao se referir aos Blocos Burlescos de Pelotas, atenta para características muito semelhantes aos Blocos Burlescos de Bagé como: "Desfilam satirizando tudo e todos. Apresentam carros alegóricos montados praticamente sem nenhum recurso financeiro, mas com muita criatividade, o que se observa também nas muitas fantasias. Entre elas, a antiga tradição dos homens saírem vestidos de mulheres, com produções de figurino que vão do mais chique aos mais chulo, tudo muito democraticamente”. (MAIA, 2008, p.20). Umas das principais características que os Blocos Burlescos levam para a avenida são as alegorias de mão, feitas na sua maioria com papelão, onde são feito desenhos alusivos ao enredo. Os Blocos Carnavalescos apresentam um modelo de desfile parecido com as Escolas de Samba, com cerca de dois carros alegóricos, cinco alas e fantasias alusivas ao enredo. Já as Escolas de Samba levam pra avenida em torno de três carros alegóricos, mais elaborados e arrojados que

\footnotetext{
${ }^{2}$ Comunidade do Alto da Santa Casa é um bairro localizado na região central da cidade de Bagé. Leva esse nome pelo fato de se encontrar perto do Hospital Santa Casa de Caridade e por estar em uma região mais elevada, uma parte alta da cidade.

${ }^{3}$ Sociedade Esportiva Recreativa Aimoré é um time de futebol amador, fundado em 1956 na cidade de Bagé. Sua sede se localiza na comunidade do Alto da Santa Casa na rua 18 de Maio, região central da cidade.
} 
dos Blocos Carnavalescos, com cerca de dez alas, mestre-sala e porta-bandeira e uma bateria que pode chegar a 70 pessoas. Cada categoria recebe o julgamento de jurados oriundos de cidades vizinhas, ou até mesmo de Porto Alegre, que darão suas notas de acordo com os quesitos exigidos por cada categoria.

O samba, desde a década de 1980 até os desfiles atuais, é um dos motores que impulsiona os blocos. Seguindo um enredo, os sambas são cantados por intérpretes, que também são julgados pelos jurados. Com isso, tanto os Blocos Burlescos como os Carnavalescos e as Escolas de Samba tem de seguir uma série de critérios, como por exemplo, as alegorias de mão e carros alegóricos para os Burlescos, as alas, fantasias, porta estandarte e carros alegóricos para as categorias Carnavalesco e Escolas de Samba, e pra todas as categorias, o samba enredo.

Analisar o samba, entendendo o processo de hibridização cultural atrelado aos processos de globalização podem ajudar a entender as transformações em que o carnaval de rua de Bagé sofreu nos últimos anos, pois assim se percebe que há uma ligação, ou seja, um diálogo do carnaval interiorano com os carnavais dos grandes centros, seja pela interação ou incorporação de instrumentos como fruto de uma relação das classes populares ou mesmo pela apropriação da indústria cultural no meio carnavalesco. Sendo assim, este trabalho procura trazer apontamentos das transformações em que o samba, na esfera do Bloco Burlesco Brasa Viva vem sofrendo ao longo dos anos.

\section{Brasa Viva comunica, rompendo na avenida.}

Discutir o carnaval em Bagé, especialmente os Blocos Burlescos, me parece ser uma tarefa difícil, mas ao mesmo tempo necessária. Por muitos anos pude perceber, de maneira empírica, o quanto esse período se transformou e o quanto se transformará mais diversos sentidos. Seja na estrutura do carnaval como um todo ou dentro das próprias entidades, que ao longo dos anos abrem mão de suas brincadeiras e sátiras com muito humor, para se colocar em destaque no cenário competitivo. Tenho um envolvimento desde criança com o carnaval de rua de Bagé, no qual sempre desfilei em diversos Blocos Burlescos da cidade. Desde que comecei a me envolver com o carnaval, sempre naturalizei a ideia dos sambas terem um enredo, um intérprete, cavaquinho e violão. Mas foi só para a realização de um trabalho da faculdade, no qual pude buscar relatos de moradores do Alto da Santa Casa, como os fundadores do Brasa Viva Alípio Dias e Antônio Ritta, que pude perceber que muita coisa havia mudado não só no carnaval como estrutura (desfile, fantasia, carros alegóricos) mas também no quesito samba. 
O antropólogo Roberto Da Matta (1997) aponta o carnaval como um processo de inversão e a negação das estruturas de poder na sociedade, um espaço democrático, diferentemente da sociedade, onde as estruturas de poder são colocadas em cheque e muitas vezes satirizadas. Analisando nessa perspectiva, entendo que por mais que o carnaval seja um espaço de socialização e de quebra dessa ordem, os Blocos Burlescos Bageense e o Bloco Brasa Viva tendem ao longo dos anos a reproduzirem um desfile colocado justamente por essa ordem, um desfile sem humor, sátiras e tudo aquilo que sempre fez parte da esfera burlesca do carnaval de Bagé.

Entre as mais diversas mudanças ocorridas no carnaval de rua de Bagé, está o samba. Muito presente em diversos carnavais do Brasil, o enredo é um quesito obrigatório, onde a entidade tem que trazer para a avenida um tema, sendo este representado em um samba, o samba enredo. Antônio Ritta, fundador do Brasa Viva se recorda de como eram os sambas na década de 1980:

\begin{abstract}
Não existia tema [...] nós saía cantando Baiana, mande água pra iô iô, todas aquelas

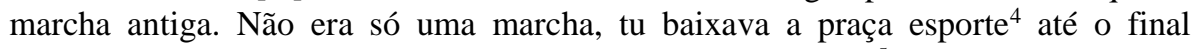
cantando o que tu quisesse. Não tinha tema, samba enredo $[\ldots]^{5}$
\end{abstract}

Percebemos nas fala de Antônio Jorge um carnaval descompromissado, diferente dos carnavais atuais, onde o bloco é obrigado a desfilar com um samba enredo, por exemplo, e até mesmo com um tempo de desfile, algo que na década de 1980 não existia.

Tido como uns dos gêneros mais conhecidos da música popular brasileira, que já foi tratado como marginal, hoje o samba é um dos retratos mais fortes da cultura brasileira (TORRES, 2014) e muito presente na cultura das entidades carnavalescas de Bagé. Sendo o motor que impulsiona os Blocos, o samba sempre esteve presente na comunidade do Alto da Santa Casa, local onde o Bloco Burlesco Brasa Viva está inserido. Diversos são os relatos de grandes sambistas que ajudaram a construir a história do bloco, sejam com grandes letras ganhadoras do carnaval ou mesmo animando os almoços e jantares na sede da entidade. Antônio Ritta se recorda de sambistas do Alto da Santa Casa:

Antigamente, o Airton Miranda, o Xiti, cantava pelo litro de vinho que nós tomava junto, o Airton Miranda, o Xiti. O Chocolate que era outro músico da noite, que já é falecido, cantava pelo um vale de dois pila, três pila, um vinho. O finado Palmo, pai

\footnotetext{
${ }^{4}$ Praça Esporte é uma praça localizada entre a Avenida Sete de Setembro, Rua Marechal Deodoro, Avenida Presidente Vargas e Marechal Floriano. Até a década de 1990 os desfiles do carnaval de rua de Bagé aconteciam na Av. Sete de Setembro.

${ }^{5}$ Entrevista realizada com Antônio Ritta, no dia 30 de Agosto de 2015.
} 
do Tiagão, músico profissional da noite, aposentado da CEEE [...] tocavam pelo amor, pelo carnaval (Antônio Ritta, 30/08/2015).

Analisar o samba como um processo híbrido, ou seja, uma prática multicultural e que traz consigo uma ideia de ruptura com a pureza (CANCLINI, 2003) é poder entender que a medida que as interações de determinados grupos sociais acontecem, novas práticas surgem. Pensar o hibridismo cultural na perspectiva do capitalismo também é importante, pois ao longo dos anos a indústria cultural se apropriou do carnaval e do samba, passando assim a ser consumido por um público, ou seja, o samba antes manifestado por determinado grupo social, passa a ser alterado pela indústria fonográfica com o objetivo de ser consumido pela cultura de massa.

Mancebo (2002) argumenta que cultura e economia estão entrelaçadas, pois os bens culturais em uma sociedade capitalista tendem a se tornar um produto a ser consumido. Com o samba no carnaval de rua de Bagé não foi diferente. Assim que o Bloco Brasa Viva é fundado, em 1968, o que existiam eram músicos moradores da comunidade do Alto e que tinham como objetivo retratar o seu cotidiano, sendo assim, podemos entender o samba do Bloco Brasa Viva como manifestação cultural. Num segundo momento, já na década de 1980, mais precisamente 1983, ano em que a entidade se insere no cenário competitivo, o samba já começava a sofrer com as influencias e padronizações do carnaval do sudeste, mais precisamente das Escolas de Samba do Rio de Janeiro.

Acredito que o carnaval de rua de Bagé pode ser entendido como um processo de hibridização, pois ao longo dos anos muitas práticas e interações foram acontecendo nessa esfera, fazendo com que houvesse uma mudança significativa não só na estrutura de organização do carnaval, mas também nos blocos, mudanças que nem sempre foram naturalizadas, como podemos perceber na fala de Alípio Dias, fundador do Bloco Burlesco Brasa Viva:

Nós criava, é como eu te disse, tu criava as coisa [...] tu não tinha que mostrar, não tinha tema, tu criava. Pra basta que nós fomo lá no Uruguai de caminhão, uma vez chovendo nós fomo lá no Uruguai e trouxemo o Barney, o Mickey, trouxemo um troço de avião, trouxemo tudo lá [...] tu criava, tu cria, não um tema agora, que tu tem que fazer essa bobagem de tema. ${ }^{6}$

Napolitano (2012) aponta que a música ajuda a pensar a sociedade, sendo de extrema importância para entendermos um determinado período histórico, sendo a canção importante não só para ouvirmos e sim para pensarmos e o samba sempre se deu dessa maneira no

\footnotetext{
${ }^{6}$ Entrevista realizada com Alípio Dias no dia 29 de Agosto de 2015.
} 
contexto das entidades carnavalescas de Bagé e no bloco Brasa Viva. Diversas são as canções que contam um período da história do carnaval de Bagé e ajudam a entender o contexto no qual os blocos Burlescos estão inseridos. Pensar a música, mais precisamente o samba, no contexto do Brasa Viva é uma tarefa importante, pois o contato com as canções de sambistas e moradores do Alto ajudam não só a perceber o samba em um contexto local, como também nacional. A cidade de Bagé conta com muitas comunidades e o Alto não é diferente. Ali o samba se dá de maneira natural, tendo em vista que sempre existiram blocos de rua e por conta disso sempre existiram compositores e músicos. Sendo assim, pude entender o processo de transformação que o samba passou e tem passado, tanto pelo ponto de vista do carnaval como no seu contexto diário e local.

Nos primeiros carnavais do Bloco Burlesco Brasa Viva, o samba era cantado de maneira experimental e improvisado, ou seja, sem preocupação com um enredo específico e sem o compromisso de seguir somente uma canção. As letras partiam muitas vezes do improviso, muito influenciado pelo gênero musical oriundo do Rio de Janeiro chamado Partido Alto ${ }^{7}$. Com isso, já se percebe uma relação híbrida do samba cantado no Rio de Janeiro com o samba cantado em Bagé. Por mais que as duas cidades estejam muito distantes uma da outra, as relações de determinados grupos sociais são sentidas e percebidas em suas manifestações. Entendendo o hibridismo como um processo multicultural, de diálogo entre diversas culturas (CANCLINI, 2003), fica evidente que por mais que exista um distanciamento, do ponto de vista geográfico, há uma interação, por isso o samba pode ser entendido como um processo híbrido, não mais genuíno e sim em constante mudança.

Para dar um exemplo de como o samba sofreu esse processo de hibridização, trago o trecho do samba composto por Airton Miranda na década de 1980 e o samba escrito por Diego Rosa para o carnaval de 2010:

Saí da vila

Saí da vila fui sambar lá no asfalto, o meu nome vem lá do Alto Brasa Viva vem mostrar ô-ô-ô-ô, como é grande o carnaval, ô-ô-ô-ô Fazer samba de repente, ô-ô-ô-ô pra nós é natural Olha amor, é uma lágrima sentida, Brasa Viva na avenida fantasia e carnaval.

Airton Miranda

Com o samba escrito por Aírton Miranda, morador da comunidade do Alto da Santa Casa, podemos notar nitidamente o contexto onde Airton estava inserido. A própria distinção que o autor faz entre vila e asfalto ajuda a entender o distanciamento entre dois mundos

\footnotetext{
${ }^{7}$ Improvisação costumeira das rodas de samba no Rio de Janeiro, apoiado numa célula-mãe, o estribilho, com base no qual corriam soltos os versos improvisados. (Adalberto Paranhos, 2003, p. 5)
} 
paralelos e ao mesmo tempo o entendimento de Airton com a sua realidade. A letra é um fator de entendimento de uma realidade subalterna no qual o bloco está inserido e a naturalidade com que o samba está presente no dia a dia desse grupo social. Saí da Vila foi escrito na década de 1980, contexto em que o carnaval de rua de Bagé, mais precisamente a categoria Burlesca, estava no seu apogeu.

A seguir, trago o samba do carnaval de 2010:

\author{
Brasa Viva Galopando no Brasil \\ Atravessei o meu Brasil, estava em busca de aventura \\ Me deparei, com uma nação que é uma flor de formosura \\ De norte a sul o Brasa vem pra te mostrar com atenção \\ As belezas dessa nação, que é o berço da miscigenação \\ Lá no norte, povo unido, gente unida braço forte \\ Defendendo nosso futuro a Amazônia que é o pulmão do mundo \\ No nordeste, Olodum, maracatu, cabra da peste \\ Tanta riqueza nunca se viu, lá no sudeste coração do meu Brasil \\ No centro-oeste a capital que rege nossas leis \\ Projetada e construída sem esquina vejam vocês \\ Com riqueza, tão natural no mato grosso e no pantanal \\ No lombo de um cavalo eu apeio lá no sul \\ No meu Rio Grande a tradição é repassada geração em geração \\ Tem churrasco, tem chimarrão na amizade na roda de mão em mão \\ Mas quando chega o carnaval, eu crio asas \\ Vou pro Brasa no Alto da Santa Casa.
}

Ao observar o samba composto por Diego Rosa, morador da comunidade do Alto, já podemos perceber que se trata de um enredo, com estrutura, ilustrativo e que segue uma ordem de tempo. Fica nítido que as duas letras analisadas já estão completamente afastadas, seja do ponto de vista estrutural ou mesmo pelo objetivo. Enquanto o samba de Aírton Miranda nos mostra um determinado contexto, explícito em um sambista, o de Diego Rosa se trata de um enredo com a temática nacionalista. Por mais que haja esse distanciamento, a segunda letra também é rica do ponto de vista cultural, pois no trecho em que fala do Olodum e Maracatu já abre a possibilidade de falarmos de hibridismo cultural, pois esses dois gêneros também passaram por um processo de hibridização, sendo que o Olodum também é uma batida muito usada nas baterias dos blocos burlescos de Bagé.

Mas não só nas letras podemos perceber o hibridismo no samba. A própria incorporação de novos elementos, como por exemplo, instrumentos musicais nos indica uma relação híbrida no samba. Percebemos isso no Sopapo $^{8}$, um instrumento oriundo das relações

\footnotetext{
${ }^{8}$ O Sopapo, um gênero de tambor de grandes dimensões conhecido hoje nas cidades de Rio Grande, Pelotas e Porto Alegre, é cercado por incertezas quanto às suas origens e circulação. Produto da reconstrução diaspórica, atribuído aos escravos trabalhadores nas charqueadas em Pelotas e Rio Grande, no século XIX, o instrumento foi
} 
diaspóricas africanas e que foi disseminado nas cidades de Rio Grande e Pelotas, para depois chegar à Bagé. Com a inserção do Sopapo no Bloco Burlesco Brasa Viva, podemos perceber que um instrumento pode ser analisado do ponto de vista do hibridismo, pois esse instrumento, trazido pelos africanos com o intuito de materializar uma identidade, ao tempo, foi se disseminando até achegar as escolas de Samba de Pelotas e posteriormente aos Blocos Burlescos de Bagé.

Voltando aos trechos dos sambas de Airton Miranda e Diego Rosa, podemos perceber nas letras uma mudança brusca no jeito de compor um samba. Um manifestado de maneira natural por um morador da comunidade e o outro com um enredo, organizado e padronizado. Um ponto chave para que houvesse essa mudança foi à indústria cultural, que se apropriou do carnaval como um produto a ser consumido, seguindo uma lógica globalizada, onde se busca cada vez mais uma unificação cultural (MANCEBO, 2002), pois as características do carnaval das Escolas do Rio de Janeiro foram apropriadas pela indústria cultural nos carnavais interioranos. Felipe Ferreira (2012) aponta para as tensões entre os compositores das Escolas de Samba do Rio de Janeiro, tendo em vista a quantia em dinheiro que será pago para o samba enredo ganhador através de direito autoral e após a gravação e comercialização do CD com os sambas do Grupo Especial. Percebemos com essas tensões a forte ligação da indústria cultural com o carnaval.

Enfim, o samba acaba se configurando como relevante meio para os estudos sobre hibridismo cultural, pois em suas letras, percebemos as narrativas e histórias locais das classes populares (FRANÇA, 2009).

\section{Considerações finais}

Portanto, pensar o samba como um processo híbrido, devido às relações vivenciadas não só no campo do carnaval, mas também no contexto de um grupo social, é entender que as diversas manifestações culturais existentes na sociedade fazem com que determinadas manifestações não permaneçam estáticas. Dessa maneira, podemos ver o hibridismo no samba do Bloco Burlesco Brasa Viva, que ao longo dos anos passou por um processo de transformação. O que antes era manifestado de maneira natural pelos sambistas da comunidade, passou a ser "interpretado", seguindo um enredo e uma estrutura padrão.

amplamente usado a partir da década de 1940 em escolas de sambas nestas cidades, conferindo particularidades ao samba executado pelas baterias destas escolas. O tempo promoveu uma migração do instrumento para outros contextos. Artistas e grupo musicais se apropriaram do instrumento no final da década de 1990, ressemantizando sua sonoridade e conferindo status diferenciado ao Sopapo, como elemento identitário e ideológico. (Mario Maia, 2008, p. 13-14). 
Percebemos também o processo de hibridização do samba instrumental, devido aos cruzamentos e influências que fez com que novos elementos fossem incorporados no contexto do carnaval Bageense.

Sendo assim, o hibridismo está completamente ligado à identidade de um grupo social, pois assim que migramos para outro contexto, além de levarmos as nossas características e identificações, seremos também afetados pelo novo local. Identidade esta percebida na letra de Airton Miranda com o samba Saí da Vila.

Por conta de todo um processo de massificação e padronização que o carnaval de rua de Bagé vem sofrendo ao longo dos anos, fica evidente que há uma situação de choque e conflito, pois nem sempre as relações e experiências tendem a serem positivas, como no caso do samba. Bhabha (1998) argumenta o hibridismo como contestação ao discurso hegemônico, ou seja, que as diferenças culturais sejam observadas, o que podemos perceber nas relações entre o samba do Bloco Burlesco Brasa Viva e a indústria cultural, que se apropria cada vez mais do universo carnavalesco.

Portanto, o hibridismo cultural é importante e necessário, pois está ligado as relações de culturas diferentes, um processo multicultural e que ajuda a formar a identidade de um indivíduo ou de determinado grupo social. Mas apesar de necessário, traz aspectos positivos e negativos, tendo em vista as mudanças ocorridas com a padronização dos sambas e sua apropriação pela indústria cultural, que nem sempre serão assimiladas e naturalizadas pelos agentes envolvidos no carnaval.

\section{Referências}

BHABHA, Homi K. O local da cultura. Belo Horizonte: UFMG, 1998.

CANCLINI, Néstor Garcia. Culturas Híbridas: Estratégias para entrar e sair da modernidade. São Paulo: Edusp, 2003.

COELHO, Teixeira. O que é indústria cultural. $2^{\mathrm{a}}$ ed. São Paulo, SP: Brasiliense, 1993.

DAMATTA, Roberto. Carnavais, Malandros e Heróis: Para uma Sociologia do dilema Brasileiro. Rio de Janeiro: Rocco, 1997.

FERREIRA, Felipe. Escolas de Samba: uma organização possível. Sistemas \& Gestão 7 (2012) pp 164-172.

FRANÇA, Maria Fernanda. O samba como comunicador do hibridismo cultural: o subalterno e o hegemônico nas músicas de Adoniran Barbosa. Intercom: XIV Congresso de Ciências da Comunicação na Região Sudeste: Rio de Janeiro, 2009. 

e-ISSN 2016/Atual: 2525-7870 | e-ISSN 2015/2016: 2447-018X

MAIA, Mário de Souza. O Sopapo e o Cabobu: Etnografia de uma Tradição Percussiva no Extremo Sul do Brasil. Porto Alegre: UFRGS, 2008 (Tese de Doutorado).

MANCEBO, Deise. Globalização, Cultura e Subjetividade: Discussão a partir dos meios de comunicação de massa. Psicologia: Teoria e Pesquisa. Set-Dez 2002, Vol. 18 n. 3, p. 289295.

NAPOLITANO, Marcos. História e Música. Belo Horizonte: Autêntica, 2002.

PARANHOS, Adalberto. A invenção do Brasil como terra do samba: os sambistas e sua afirmação social. História: São Paulo, 22 (1) 81-113, 2003.

TORRES, Aline Nascimento Barrozo. Samba Enredo. Apropriação e transformação da cultura Negra: A música como valor e fator de difusão cultural e de organização do Carnaval na cidade de São Paulo. CELACC/ECA/USP, 2014 (Trabalho de Conclusão de Curso). 